\title{
Identifying Optimal Cutting Parameters in Drilling of Titanium Aluminum Vanadium Using Finite Element Analysis
}

\author{
M. M. Reddy ${ }^{1 *}$, S. R. Kostka ${ }^{1}$, N. S. Reddy ${ }^{2}$ \\ ${ }^{1}$ Department of Mechanical Engineering, Faculty of Engineering and Science, Curtin University Malaysia, Miri, Malaysia \\ ${ }^{2}$ Department of Metallic \& Materials Engineering, Gyeongsang National University, Jinju, South Korea \\ Email: ^mohan.m@curtin.edu.my
}

How to cite this paper: Reddy, M.M., Kostka, S.R. and Reddy, N.S. (2020) Identifying Optimal Cutting Parameters in Drilling of Titanium Aluminum Vanadium Using Finite Element Analysis. Journal of Surface Engineered Materials and Advanced Technology, 10, 55-62.

https://doi.org/10.4236/jsemat.2020.103004

Received: June 14, 2020

Accepted: July 9, 2020

Published: July 12, 2020

Copyright $\odot 2020$ by author(s) and Scientific Research Publishing Inc. This work is licensed under the Creative Commons Attribution International License (CC BY 4.0).

http://creativecommons.org/licenses/by/4.0/

\section{(c) (i) Open Access}

\begin{abstract}
Titanium alloys are widely used in the aerospace industries because of their excellent strength-to-weight ratio, high resistance to corrosion, high chemical reactivity and low thermal conductivity and ability to withstand high temperatures. However, these properties make titanium alloys difficult to machine. Drilling of titanium alloy may generate high temperature and high cutting forces. This paper is aimed at determining the suitable cutting parameters in the drilling of titanium alloys to minimize the cutting temperature and cutting forces. A finite element 3D model of the drilling process is simulated in this research. A combination of drilling speeds and feed rates are simulated to obtain the resulting responses of cutting force and temperature. The central composite design (CCD) is used to generate different combinations of cutting parameters to reduce the number of experiments and optimize the temperature and cutting force responses. Results show at the drilling speed of 5000 $\mathrm{rpm}$ with a feed rate of $0.1 \mathrm{~mm} / \mathrm{rev}$, temperature and cutting force significantly reduced.
\end{abstract}

\section{Keywords}

Titanium Alloys, Design of Experiments, Drilling, Cutting Force

\section{Introduction}

Titanium is known to be very difficult to machine, despite its excellent properties and wide usage. The reason for this is due to their poor thermal conductivity [1]. The heat generated while machining does not dissipate because of the weak thermal conductivity and this will cause a definite reduction in tool life. Heat is 
build-up around the cutting edge and tool face. When the temperature escalates during machining, it causes tool wear or failure due to galling, smearing as well as welding. Chip formation also occurs and is caused by dissimilarity of the shear strains in the chip and is bounded by a narrow band that forms serrated chips [2]. Conventional cutting tools that work for other traditional industrial materials do not work with Titanium even at normal cutting speeds. Most researches focused on turning and end milling operations and not much work has been done on drilling of Titanium alloys. Yang et al. [1] has covered different areas of machining such as turning, milling and grinding. Therefore, it is important to participate in contributing research to identifying important parameters in drilling of Titanium and further optimize it as Titanium has shown to be thriving in aerospace industry, and continues to gain favor when it comes to the choosing of materials. Among other applications, titanium and its alloys are also widely used in chemical industries, manufacturing of turbine blades, bio-medical engineering and as bone supplement in bone grafting [3]. Isbiliar et al. [4] presented that FE model of drilling could accurately predict the cutting force, torque and stresses with respect to drilling parameters. Parameters of machining that are essential include cutting speed, feed rate and depth of cut. Experimental work was conducted by Sultan et al. [5] to identify the optimum cutting speed and feed rate for discontinuous chip formation with a drilling process. It was found that the lowest cutting speed as well as feed rate produced the best performance in regards to chip formation. Besides that, the material chosen for the cutting tool is vital when machining of titanium is concerned. The important and influential parameters are only considered for this research paper. The influence of cutting parameters such as cutting speed, feed rate are considered to estimate the cutting force and cutting temperature. These parameters were tested and then optimized using Response Surface Methodology with the Design Expert. The research performed here is aimed at reducing the cutting temperature and cutting force which is pre-determined by the parameters tested to further improve cost and machining efficiency with regards to tool life and workpiece surface integrity. At the same time, this research looks to ultimately determine the utmost optimal parameters for Titanium drilling that can be used as reference in all future drilling activities of the Titanium material.

\section{Experimental Details}

\subsection{Workpiece Material}

The workpiece used is the Titanium Aluminum Vanadium (Ti6Al4V) with the dimensions of $12 \times 3 \times 12 \mathrm{~mm}$ for width, height and length respectively.

\section{Cutting Tool}

In this study, the cutting tool used is the standard carbide drill commonly used in industrial. The carbide drill is coated with one layer of TiAlN with a thickness of $0.007 \mathrm{~mm}$. The cutting tool has a drill diameter of $6 \mathrm{~mm}$ and a helix angle of $30^{\circ}$. 


\subsection{Design of Experiment}

The experiment was conducted to study and analyze the cutting parameters in drilling. The influence of the parameters was investigated to identify its correlation to the response, temperature and cutting force. A simulation of a TiAlN coated carbide tool drilling a Ti6Al4N workpiece material is conducted to identify the maximum cutting temperature and cutting force acting on the workpiece. The testing parameters were generated using Central Composite Design which will help in reducing the number of experiments necessary. A two-level factorial is selected for the design of this experiment. CCD uses a coded factor of $-1,0$ and 1 to produce varied iterations to determine their various interactions as shown in Table 1. The drilling parameters tested are the spindle speed and feed rate. In total, 13 number of runs were generated by the software shown in Table 2. The software uses 5 center point replicates with the other 8 points being an independent interaction. The drilling parameters and CCD matrix for design and responses are shown below:

\section{Results and Discussion}

\subsection{Simulation}

The simulation was conducted using the ThirdWave Systems AdvantEdge software.

Table 1. Drilling Parameters used for study.

\begin{tabular}{cccc}
\hline Parameters & Values & \\
\hline Factorial Level & -1 & 0 & 1 \\
Spindle Speed (rpm) & 1000 & 3000 & 5000 \\
Feed Rate $(\mathrm{mm} / \mathrm{rev})$ & 0.1 & 0.55 & 1.0 \\
\hline
\end{tabular}

Table 2. CCD design matrix and responses.

\begin{tabular}{ccccc}
\hline & \multicolumn{2}{c}{ Parameters } & \multicolumn{2}{c}{ Response } \\
\hline Test No. & Speed $(\mathrm{m} / \mathrm{min})$ & Feed $(\mathrm{mm} / \mathrm{rev})$ & Temperature $\left({ }^{\circ} \mathrm{C}\right)$ & Cutting Force $(\mathrm{N})$ \\
\hline 1 & -1 & -1 & 330 & 969 \\
2 & 0 & 0 & 320 & 1753 \\
3 & 1 & -1 & 135 & 407 \\
4 & 0 & 0 & 850 & 3796 \\
5 & -1 & 1 & 720 & 6137 \\
6 & 0 & 0 & 1150 & 4192 \\
7 & 1 & 1 & 700 & 5926 \\
8 & 0 & 0 & 850 & 3903 \\
9 & 0 & 1 & 750 & 6756 \\
10 & 0 & -1 & 750 & 873 \\
11 & -1 & 0 & 800 & 4157 \\
12 & 1 & 0 & 950 & 5883 \\
13 & 0 & 0 & 1050 & 3743 \\
\hline
\end{tabular}


The responses obtained from the simulation were interpreted graphically and its numerical values were extracted to discuss and compare the different variables. From the responses obtained, 3 graphs (Figures 1-3) were plotted to obtain an approximate analysis of the results. The graphs are shown below:

From the graphs shown above, the lowest feed rate, $0.1 \mathrm{~mm} / \mathrm{rev}$ shows the lowest responses for temperature and cutting force. The values steadily decrease as the speed increases. This coincides with previous researches that state the optimal parameters for drilling require a low feed rate but high cutting speed.

\section{Cutting Force and Temperature at Various Speeds}

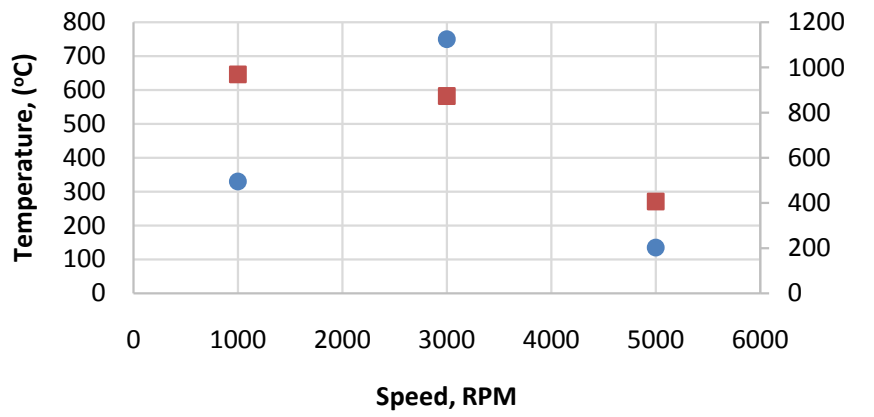

Figure 1. Cutting force and temperature at $0.1 \mathrm{~mm} / \mathrm{rev}$ feed rate.

\section{Cutting Force and Temperatures at Various Speeds}

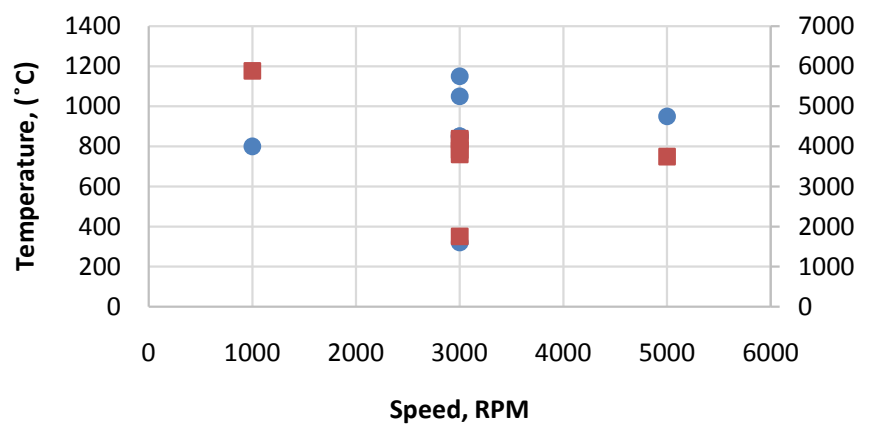

Figure 2. Cutting force and temperature at $0.55 \mathrm{~mm} / \mathrm{rev}$ feed rate.

\section{Cutting Force and Temperatures at Various Speeds}

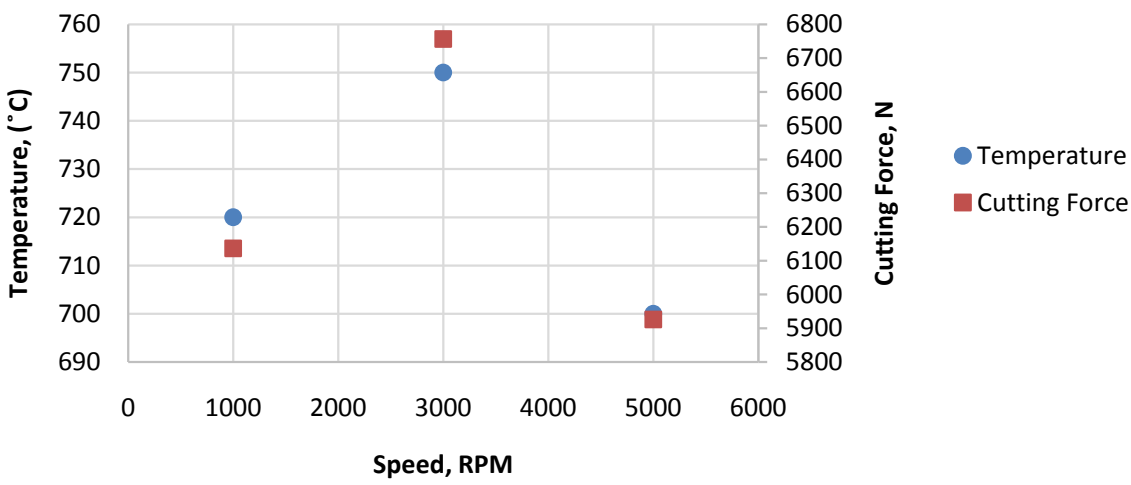

Figure 3. Cutting force and temperature at $1.0 \mathrm{~mm} / \mathrm{rev}$ feed rate. 


\subsection{Analysis of Variance (ANOVA)}

The Model F-value of 23.76 implies (Table 3) that the model is significant. There is only a $0.02 \%$ chance that an F-value this large could occur due to noise. Values of "Prob > F" less than 0.05 indicates that the model terms are significant. In this case, the feed rate is a significant model term.

\subsection{Residual Plots}

The residual plot (Figure 4) is used to examine the goodness-of-fit in regression and ANOVA. Examining residual plots helps determine where the assumptions are being met. If the assumptions are met, there will be minimal variance. The plots above show minimum variance as the points are aligned closely to the predicted line.

\subsection{Optimizing Cutting Force and Temperature}

After analyzing the variance, it is important to identify the most suitable parameters for cutting speed and feed rate. These values should be optimized to produce the smallest value for cutting force and temperature. Table 4 below shows the optimized values that meet the requirement of minimizing the responses. The confidence level was maintained at $92 \%$ with desirability of 0.92 .

The graph (Figure 5) shows the relationship between the feed rate and drilling speed with the temperature and cutting force responses. The temperature graph showed minimal changes in temperature with the various parameters. A significant drop in temperature can be observed in the graph when the feed rate is 0.1 $\mathrm{mm} / \mathrm{rev}$ and the cutting speed is $94.25 \mathrm{~m} / \mathrm{min}$. As for the cutting force response, a more significant change can be observed with the various parameters.

Table 3. ANOVA table for cutting force.

\begin{tabular}{cccccc}
\hline Source & Sum of Squares & df & Mean Square & F Value & p-value Prob > F \\
\hline Model & $4.591 \mathrm{E}+007$ & 2 & $2.296 \mathrm{E}+007$ & 23.76 & 0.0002 \\
A-Speed & $1.515 \mathrm{E}+005$ & 1 & $1.515 \mathrm{E}+005$ & 0.16 & 0.7005 \\
B-Feed & $4.576 \mathrm{E}+007$ & 1 & $4.576 \mathrm{E}+007$ & 47.36 & $<0.0001$ \\
Residual & $9.663 \mathrm{E}+006$ & 10 & $9.663 \mathrm{E}+006$ & & 0.5198 \\
Lack of fit & $5.826 \mathrm{E}+006$ & 6 & $9.709 \mathrm{E}+005$ & 1.01 & \\
Pure Error & $3.873 \mathrm{E}+006$ & 4 & $9.594 \mathrm{E}+005$ & & \\
Cor Total & $5.558 \mathrm{E}+007$ & 12 & & & \\
\hline
\end{tabular}

Table 4. Optimum cutting parameters for temperature and cutting force.

\begin{tabular}{cccccc}
\hline No. & Speed & Feed & Temperature & Cutting Force & Desirability \\
\hline 1 & 94.25 & 0.100 & 310.91 & 1127.64 & 0.92 \\
2 & 94.25 & 0.104 & 316.68 & 1150.81 & 0.92 \\
3 & 93.378 & 0.100 & 317.59 & 1123.97 & 0.92 \\
\hline
\end{tabular}



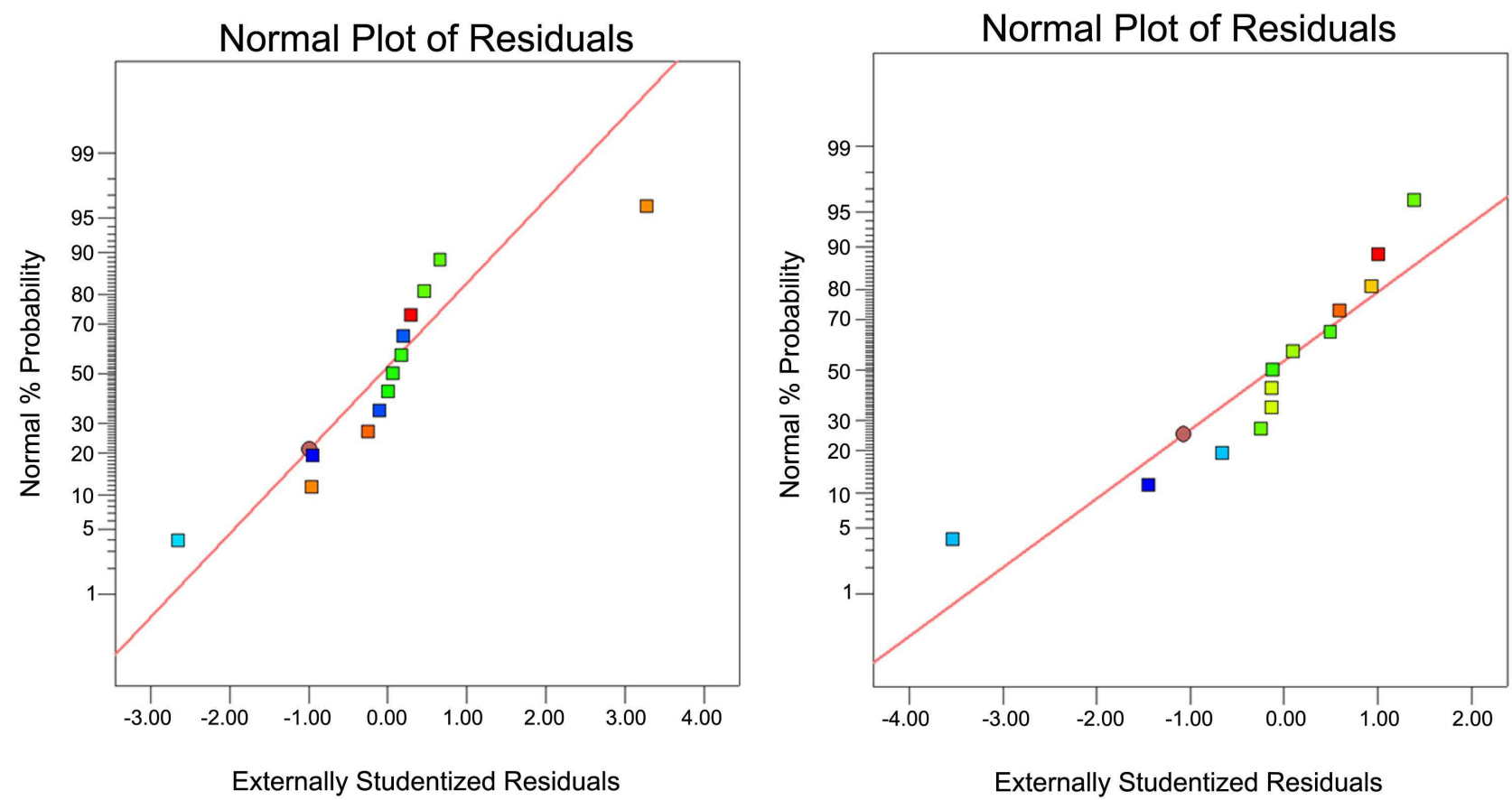

Figure 4. Residual plots.
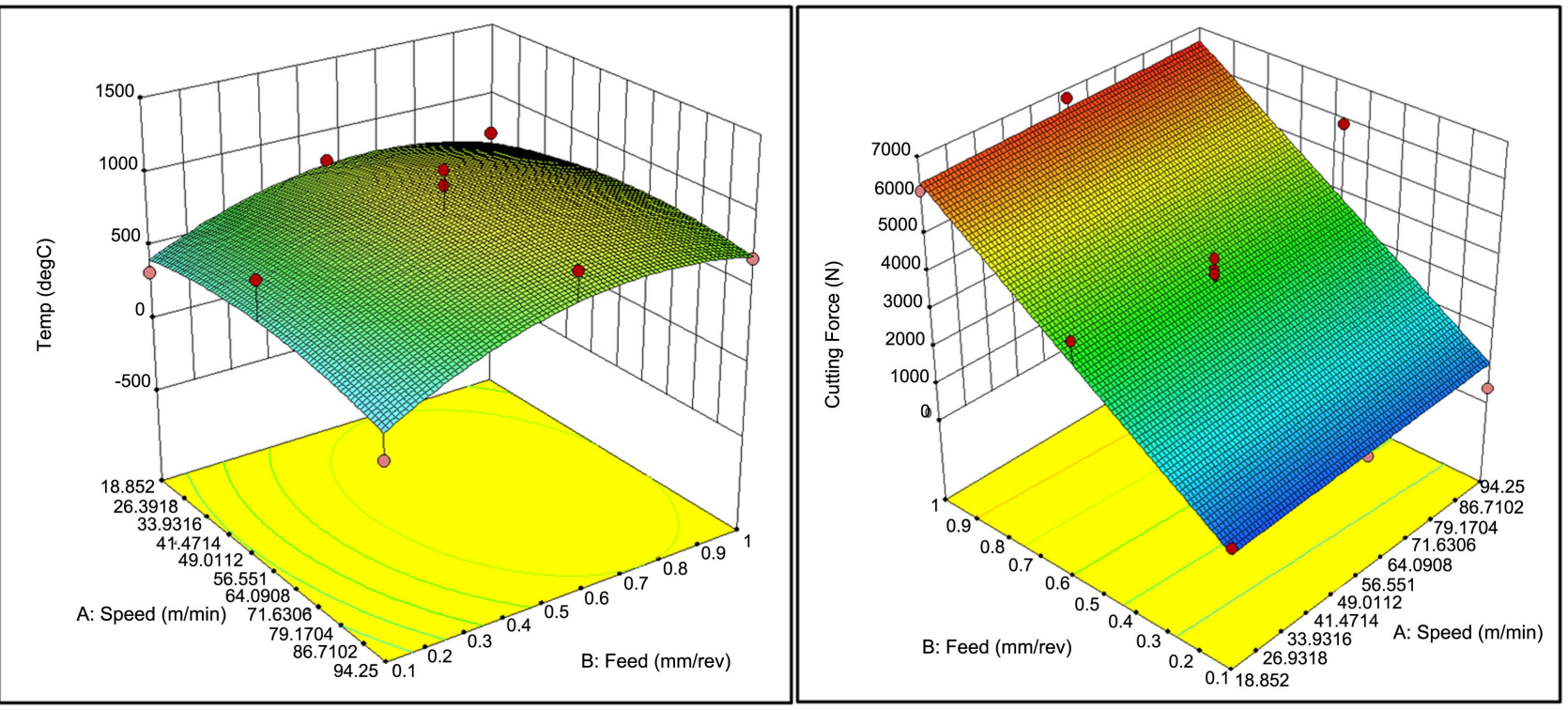

Figure 5. 3D plots of temperature and cutting force.

The lowest feed rate and cutting speed produce significantly lower temperature compared to the highest feed rate and cutting speed. However, to reduce both responses, the feed rate was chosen to be the lowest value at $0.1 \mathrm{~mm} / \mathrm{rev}$ whilst the cutting speed has the maximum value of $94.25 \mathrm{~m} / \mathrm{min}$.

The cutting force and temperature graph above further depict the predicted response with respect to the drilling parameters. The contour plots in Figure 6 helps to understand the relationship between the parameters and the responses. While other combinations of parameters may produce lower responses, CCD 


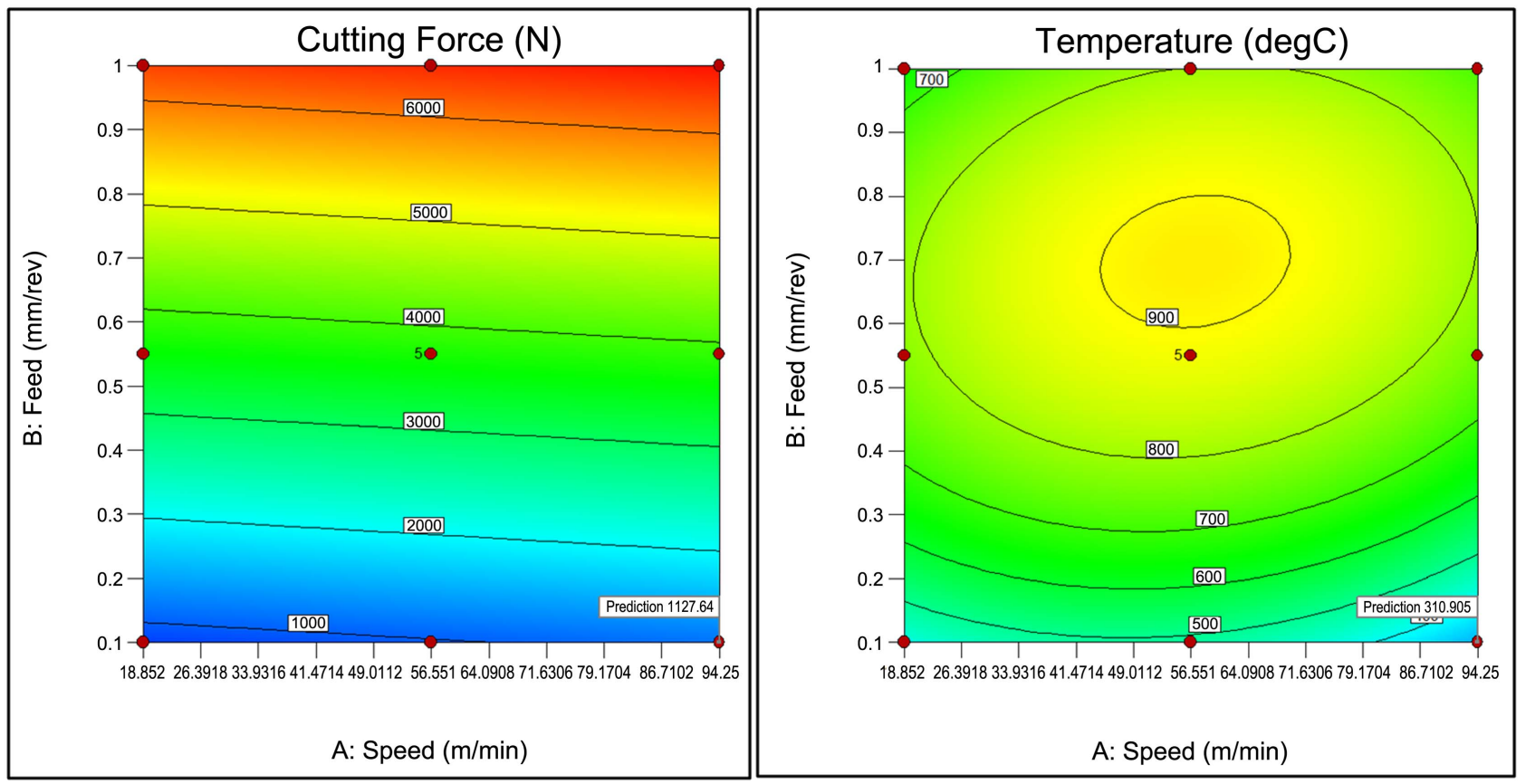

Figure 6. Contour plots of temperature and cutting force.

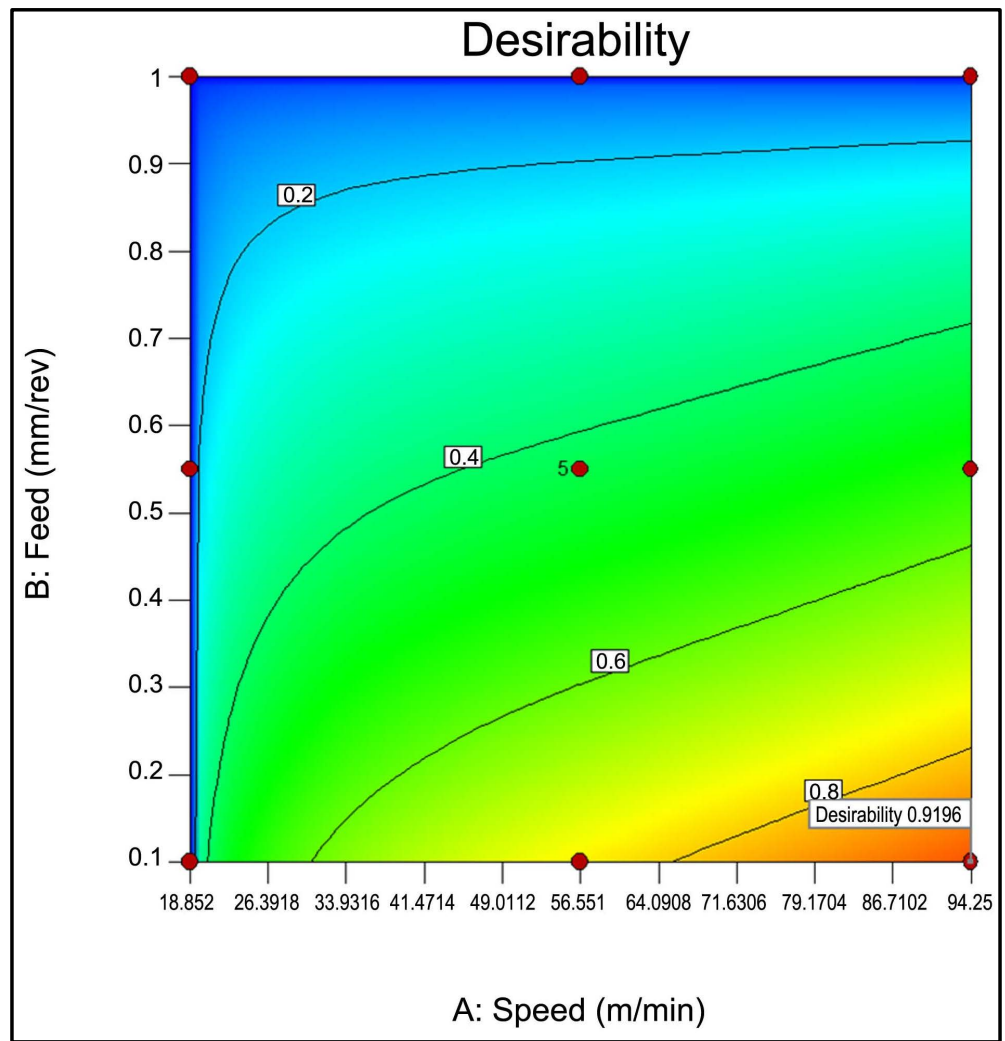

Figure 7. Desirability of the responses.

uses the selection criteria of lowering the responses to determine the best result for both temperature and cutting force simultaneously. At $94.25 \mathrm{~m} / \mathrm{min}$ and 0.1 $\mathrm{mm} / \mathrm{rev}$, the desirability of the responses (Figure 7) is highest at $92.1 \%$. The 
yellow zone in the graph (Figure 7) shows that the predicted values are in range of the desired criteria.

\section{Conclusions}

To conclude this research paper, the optimal parameters for the drilling of titanium have been found through the simulation and optimization done for this research.

1) A Central Composite Design (CCD) of response surface methodology (RSM) has been adopted to determine the parametric combination (treatment) for conducting the experiments and obtain maximum process-related information with the least number of experimental runs.

2) Finite element analysis has been used to develop $3 \mathrm{D}$ model and perform the drilling simulation using Advant Edge.

3) The lowest responses for the temperature and cutting force obtained from the simulation are $310.91^{\circ} \mathrm{C}$ and $1127.64 \mathrm{~N}$ with the optimal cutting parameters at $94.25 \mathrm{~m} / \mathrm{min}$ and $0.1 \mathrm{~mm} / \mathrm{rev}$ for drilling speed and feed rate respectively.

\section{Acknowledgements}

The authors wish to thank Ministry of higher education, Malaysia, for providing the fund through FRGS grant for this work

\section{Conflicts of Interest}

The authors declare no conflicts of interest regarding the publication of this paper.

\section{References}

[1] Yang, X.P. and Richard Liu, C. (1999) Machining Titanium and Its Alloys. Machining Science and Technology, 3, 107-139. https://doi.org/10.1080/10940349908945686

[2] Rahman, M., Wong, Y.S. and Zareena, A.R. (2003) Machinability of Titanium Alloys. JSME International Journal, 46, 107-115.

[3] Chatterjee, S., Mahapatra, S.S. and Abhishek, K. (2016) Simulation and Optimization of Machining Parameters in Drilling of Titanium Alloys. Simulation Modelling Practice and Theory, 62, 31-48. https://doi.org/10.1016/j.simpat.2015.12.004

[4] Isbilir, O. and Ghassemieh, E. (2011) Finite Element Analysis of Drilling of Titanium Alloy. Procedia Engineering, 10, 1877-1882. https://doi.org/10.1016/j.proeng.2011.04.312

[5] Sultan, A.Z., Sharif, S. and Kurniawan, D. (2015) Chip Formation When Drilling AISI 316L Stainless Steel Using Carbide Twist Drill. Procedia Manufacturing, 2, 224-229. https://doi.org/10.1016/j.promfg.2015.07.039 